\title{
Health Prospect

\section{Doing Focus Groups in the Health Field: Some Lessons from Nepal}

van Teijlingen $\mathrm{E}^{1}$, Simkhada $\mathrm{P}^{2}$, Stephens $\mathrm{J}^{3}$

${ }^{2}$ Padam Simkhada: Senior Lecturer, ScHARR, University of Sheffield, UK; Visiting Professor, MMIHS, Nepal

\section{Summary}

3 Jane Stephens: Director, Green Tara Trust, UK

This paper addresses two research issues, one related to the running of focus groups and one more generally, on the link between researchers and local health officials. The objective of this article is to alert potential focus group researchers of some of the challenges related to conducting focus groups in rural areas. Our view-point article highlights the key issues of our experience in conducting focus groups in Nepal. Furthermore, it reflects on likely reasons why the challenges occurred and, where possible, offers some solutions to improve the running of focus groups.

\section{Introduction}

Most health, public health and medical researches in Nepal are either quantitative or clinical. A review of the published health literature found that $78 \%$ of papers were based on quantitative research. (1) Unsurprisingly, Nepal, like many developing countries, lacks capacity in qualitative research. This paper centres on one particular qualitative method namely, focus group research. Widely used in market research and in the sciences, focus groups are now a key element of health services and health care research. (2) In Nepal, this method has been used in various sectors, for example, the areas of reproductive and sexual health. (3-5) Based on our experience of conducting several focus group studies, this paper reflects on some of the lessons learnt from using the method in $\mathrm{Ne}$ pal. Levels of illiteracy are still high in some sub-groups of the population in Nepal, particularly in older people, especially women and those living in remote areas. This makes doing qualitative research a good option as it does not depend on participants being able to read or write or someone else reading out and writing down the answers for them as would be the case in questionnaire studies or online studies.

\section{Focus Groups in the field of Maternity Care}

As our research focuses on reproductive health and maternity care, we often need to run focus groups containing only women of reproductive age in rural communities. Our focus groups discussions are a part of larger mixedmethods evaluation which uses a cross-sectional beforeand-after study design with control and intervention communities. (6) One common problem we often face in this area is: 'How can we create a confidential and private space to conduct a focus group discussion in villages so that women can talk freely without others listening in?' This is a genuine problem with focus groups conducted outside in an open public space. As a solution, we try to book a community building, if there is one, in advance. Perhaps a local school, larger health post or temple has a room that can be hired for a (small) focus group. If there are no such buildings in the community, we try to organ- ise parallel groups for other community groups e.g. men, mother in laws, teenage girls at the same time, but usually there will still be people wanting to listen in excepts these peoples. Another option we tried was to call the focus groups workshops, since running workshops suggest 'serious' learning and this gives local people in the group a legitimate reason to shush bystanders away.

Different textbooks suggest a different minimum and maximum number of focus group participants, the range is roughly between 4 and 12, although some focus groups have up to 20 discussants. (7-8) Rather than prescribing number of participants, the main considerations should be that a focus group needs a minimum number of participants to stimulate and generate discussion, but not too many people as this may prevent quiet and shy ones from participating or facilitating the discussion. (2) In a less formal society such as a Nepalese village, it is fairly impossible to invite 12 or 15 women to a focus group and exclude their interested neighbours, especially when one relies on an open-air venue. It is then up to the researcher to decide the range and number of people needed, and once this number has been reached, for her to skillfully facilitate the focus group whilst a second person assists in trying to keep new people out by explaining that the group has started and that introducing new members would delay the process too much. One solution we tried quite successfully was to run our focus group immediately after or before an existing women's group meeting. The community knows that the women's group is running anyway which makes the tagged on focus group less exciting and hence attracts fewer outsiders.

\footnotetext{
Correspondence:

${ }^{1}$ Prof. Edwin van Teijlingen

Centre for Midwifery, Maternal \& Perinatal Health

Bournemouth House

19, Christchurch Road

Bournemouth University, England, UK.

Tel: +44 (0)1202-961564

Email: vanteijlingen@bournemouth.ac.uk
} 


\section{Location of Focus Groups}

It is considered to be a good research practice when privacy of participants is maintained, external noises are avoided and chances of interruption during the running of the focus group are reduced. All methods that textbooks suggest about the qualitative researcher creates a relaxed atmosphere in a comfortable setting to develop trust and stimulate discussion. (9-10) One of the key organisational aspects is that the researcher brings participants for a focus group at an agreed place and time. In the UK, this would normally mean sending out a letter or email inviting people to participate in a focus group next Tuesday at 14.00 in a dedicated room in, for example, a hospital or university. In rural Nepal, focus groups usually take place in the open air, someone's home or a fairly open community building where people are free to leave and enter. This means that it is hard to keep non-attendees ('outsiders') away from the focus group, it is also impossible to maintain a basic level of confidentiality/anonymity.

\section{Research Ethics}

Using focus groups, the researchers can only guarantee anonymity and confidentiality as a researcher i.e. for their own part of the study. (11) Typically, we would tell focus group participants that we will not quote their names or any identifying details in our reports and scientific papers. We ask participants to maintain confidentiality in what others said in the group, but participants rarely observe this request, and, if others are listening in, keeping confidentiality is not possible. Therefore, our solution is not to offer anonymity and confidentiality. We stress that we will not use their names in any reports or publications, but we stress to focus group participants that they need to be sensible in what they say in the focus group as what they say might be repeated by others. The latter is particularly important if people in the group and outsiders listening in all know each other (e.g. all live in the same VDC or work in the same hospital).

\section{Managing Expectation}

Often unrealistic expectations arise between researchers and programme implementers from industrialised countries and colleagues, policy-makers, communities and/ or research participants in developing countries. In our experience, local collaborators have often assumed that firstly, we have access to large sums of money and secondly, that money we do have can be used as per the community wishes. So, in a rural group discussing, the needs and focus of the community can rapidly move to people's perceived need for physical items or cash that are needed to be provided from outside sources, rather than focusing more widely on resources needed to address a problem, many of which could be sourced within that same community. When such expectations are expressed in questionnaire studies the researcher might not see them until two weeks later when the data are entered on a computer. In a focus group this expression of expectations is immediate and the facilitator has to 'react' skilfully to address the relevant issue. The researcher can help to broaden people's understanding of limited resources and help them explore potential barriers as well as solutions to these problems in their own families and communities. Thus, the solution is to discuss during or immediately after the focus group with the participants what limited resources are likely to be available to the local community. Also, like Morrison and colleagues, we tried to avoid raising expectations by introducing the focus groups "to the aims of the intervention" and then discussing and prioritising problems relevant to the intervention. (12)

\section{Linking up with Health Authorities}

Keeping stakeholders informed at all levels is important anywhere in the world. However, in the industrialised world, this is partly done through formal arrangements, by letter and email, rather than through face-to-face meetings. In Nepal, developing personal connections with stakeholders is essential to good research collaboration. For example, in order to conduct the action research in health promotion funded by the Green Tara Trust in two VDC areas, we met with various community groups, the local health post staff, the District Public Health Office, the chairs of the VDCs and other active local organizations prior to the start of the intervention and the associated research. We initially thought this groundwork was sufficient for the lifespan of our project, and six-monthly reviews of any new activities or organisations in the local area were conducted as part of the work. However, two years later a newly appointed health official did not know about our programme (i.e. there was no institutional memory). Therefore we needed to 'start' again with introductions, explain who we are and how our research programme fits in with the local area's health policy and country's strategy. We had mistakenly expected that an incoming health official would have been briefed on all local health programmes, and perhaps for them to approach us to find out more about our work. What we have now started to do is to inform local relevant people of any key steps in the research programme, if anything it is way of finding out sooner rather than later that people like the district health officer have changed.

\section{Final thoughts}

What all of us working as health researchers in Nepal are doing is to sensitise the population to the importance of research and familiarising local people with the ethical notions of anonymity and confidentiality.

\section{References:}

1. Simkhada P, Baral YR, van Teijlingen E. Health and Medical Research: A Bibliometric Review, Asia Pac J Public Health. 2010; 22: 492-500. Available from: http://aph.sagepub.com/content/22/4/492.full. pdf+html

2. Van Teijlingen ER, Pitchforth E. Focus Group Research in Family Planning and Reproductive Health Care, J Fam Plann Reprod Health Care. 2006; 32 (1): 30-32.

3. Masvie $\mathrm{H}$. The role of Tamang mothers-in-law in promoting breast feeding in Makwanpur District, Nepal, Midwifery. 2006; 22: 23-31.

4. Van Teijlingen E, Simkhada P, Ireland JCM. Lessons learnt from undertaking maternity-care research in developing countries. Evidencebased Midwifery. 2010; 8(1): 12-16. 
5. Bhandari B, Pokhrel B, Bhatta B, Karn R, Pokhrel A, Jha N. Utilization of maternal health care services in Belbari VDC of Eastern Region of Nepal, J Nobel Med Coll. 2011; 1(1): 53-58.

6. Van Teijlingen E, Simkhada P, Stephen J, Simkhada B, Woodes Rogers S, Sharma S. Making the best use of all resources: developing a health promotion intervention in rural Nepal. Health Renaissance 2012; 10(3): 229-235. Availabble from: www.healthrenaissance.org.np/uploads/7141_24852_1_PB.pdf

7. Fitzpatrick R, Davis A. Qualitative Methods for assessing health care. Qual Health Care 1994; 3:107-113.

8. Carlson B, Glenton C. What about N? A methodological study of sample-size reporting in focus group studies BMC Med Res Methodol. 2011; 11: 26. Available from: http://www.biomedcentral.com/content/pdf/14712288-11-26.pdf
9. Barbour R. Introducing qualitative research: A student guide to the craft of doing qualitative research. London: Sage, 2008.

10. Morgan D. Focus groups as qualitative research. London: Sage, 1997.

11. Gibbs A. Focus Groups Soc Res Update. 1997; 19: 4. Available from: http://sru.soc.surrey.ac.uk/SRU19.html

12. Morrison J, Osrin D, Shrestha B, Tumbahangphe KM, Tamang S, Shrestha D, Thapa S, Mesko N, Manandhar DS, Costello A. How did formative research inform the development of a women's group intervention in rural Nepal? J Perinatol. 2008; 28: S14-S22. 